MEINUNG

\author{
Kindergesundheit
}

\title{
Eine Zuckersteuer ist ein Muss
}

\author{
Kinder und Jugendliche sind immer mehr Zucker ausgesetzt. Die Politik \\ könnte den Trend stoppen - aber nicht ohne eine Extrasteuer.
}

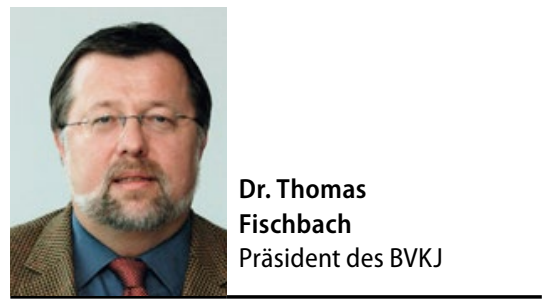

_ Zucker ist süß. Er erinnert uns an die erste prägende Geschmackserfahrung unseres Lebens, an Muttermilch. Deshalb lieben Menschen Zucker. In Deutschland verbraucht ein Mensch im Schnitt rund $35 \mathrm{~kg}$ Zucker im Jahr. Das meiste davon steckt nicht in Süßigkeiten, sondern in allen möglichen industriell produzierten Nahrungsmitteln, vor allem in süßen Getränken.

Zucker ist bitter. Denn Zucker ist schlecht für die Zähne, macht dick und sogar krank. Und Zucker macht abhängig. Je mehr sich Kinder in den ersten Lebensjahren an den süßen Geschmack gewöhnen, desto mehr mögen sie ihn ein Leben lang. Wir stehen heute vor einer Adipositasepidemie, die das Gesundheitssystem jedes Jahr Milliarden kostet. Immer mehr Kinder leiden unter ernährungsbedingtem „Alters-Diabetes“. In unseren Praxen sehen wir Vierjährige, die keinen gesunden Zahn mehr haben, und dicke Zwölfjährige, die sich kaum noch bücken können und denen Rücken und Füße weh tun.

\section{Mächtige Industrielobby}

Viele Eltern versuchen gegenzusteuern und verbieten ihren Kindern Süßigkeiten und Naschereien. Aber sie kämpfen dabei gegen eine äußerst mächtige Lobby. Die Lebensmittelindustrie versucht, zusammen mit der von ihnen beauftragten Werbeindustrie vor allem aus Kindern lebenslang treue Kunden zu machen. Sie verzieren Verpackungen mit lustigen Tierchen, schalten Werbung und schaffen Online-Welten, in denen Kinder spielerisch an süße Lebensmittel herangeführt werden. Und sie machen es Eltern äußerst schwer, informierte Kaufentscheidungen zu treffen.
Eltern merken vielfach nicht, welche Zuckerbomben sie da kaufen. Die Hersteller verschleiern den Zuckergehalt hinter Begriffen wie Maltose, Dextrose und anderen „-osen“, sie werben mit "weniger süß " und verheimlichen, dass dies nur eine vergleichende, keine objek-

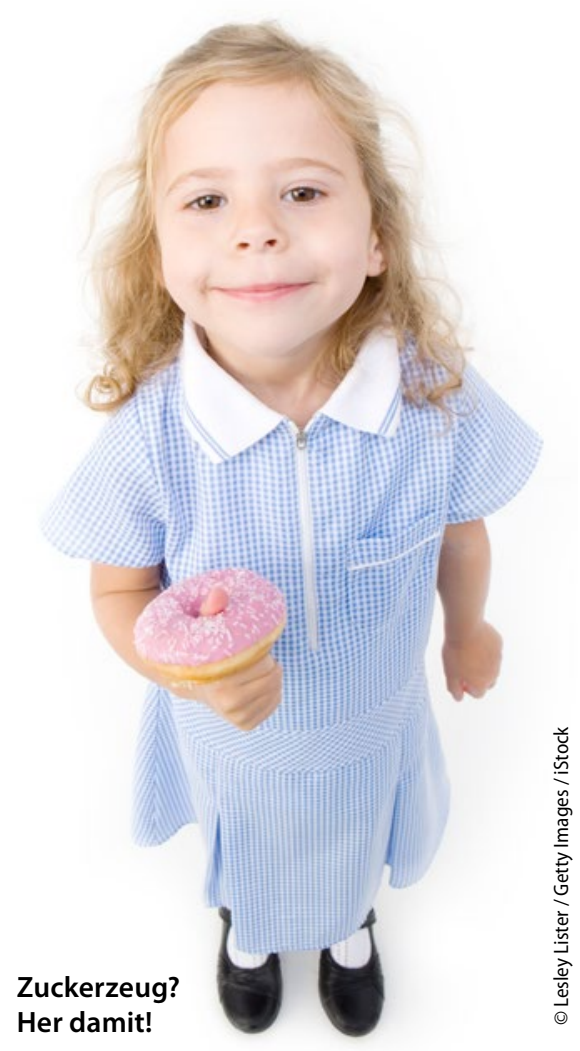

tive Aussage ist. Sie werben mit „natürlicher Süße“, „ohne Zuckerzusatz“ oder „100\% Frucht“ und verwenden Fruchtkonzentrate, Dicksäfte oder Sirups.

Süßgetränke, Softdrinks wie Limonaden, Cola und Eistee, aber auch Fruchtsäfte schaden der Gesundheit besonders. Minderjährige trinken laut KiGGS, der großen Basiserhebung zur Kinder- und Jugendgesundheit, im Schnitt mehr als zwei Gläser der Zuckerbomben pro Tag. Softdrinks, aber auch Fruchtsäfte sind deshalb so gefährlich, weil sie zusätzlich zur normalen Nahrung aufgenommen werden. Vielen Eltern ist das gar nicht klar. Vor allem Eltern mit Migrationshintergrund oder schlechter Schulbildung verstehen die komplizierten Angaben auf den Verpackungen nicht.

\section{Lebensmittelampel muss kommen}

Der Berufsverband der Kinder- und Jugendärzte (BVKJ) fordert daher seit Jahren die Lebensmittelampel, eine Zuckerabgabe, ein Werbeverbot für süße Getränke und sogenannte Kinderlebensmittel sowie die Verringerung des $\mathrm{Zu}$ ckergehalts in Lebensmitteln. Insbesondere die Lebensmittelampel würde auch Eltern, die keine großen Ernährungsoder Deutschkenntnisse haben, eine schnelle Orientierung schon vor dem Gang zur Kasse bieten.

Zusätzlich brauchen wir endlich eine Zuckersteuer nach dem Vorbild der Alkopops-Steuer. Nachdem die Politik die bei Jugendlichen überaus beliebten Schnapsmischgetränke mit einer Sondersteuer belegt hatte, sank der Absatz binnen eines Jahres um 80\%. Mit einer Zuckersteuer und damit höheren Preisen würden der Absatz von Süßgetränken deutlich zurück gehen.

Und wir brauchen mehr Aufklärung an Kitas und Schulen. Mit dem Geld, das die Kassen sparen, wenn weniger Menschen durch Fehlernährung chronisch krank werden, könnte man in dieser Hinsicht viel bewegen.

- Der Autor ist Präsident des Berufsverbands der Kinder- und Jugendärzte (BVKJ) 